\title{
Farelo de Girassol na Alimentação de Suínos em Crescimento e Terminação: Digestibilidade, Desempenho e Efeitos na Qualidade de Carcaça
}

\author{
Caio Abércio da Silva ${ }^{1}$, João Waine Pinheiro', Nilva Aparecida Nicolao Fonseca ${ }^{1}$, \\ Lizete Cabrera1, Valéria Cristina Cunha Novo², Marcos Augusto Alves da Silva ${ }^{2}$, \\ Regis Civoney Canteri², Edgar Hideaki Hoshi ${ }^{2}$
}

\begin{abstract}
RESUMO - Foram realizados dois experimentos, objetivando avaliar o farelo de girassol (FG) na alimentação de suínos em crescimento e terminação. Inicialmente, foi avaliada a digestibilidade do FG, utilizando-se oito suínos machos castrados, com peso médio inicial de 30,41 kg, alojados individualmente em gaiolas metabólicas. Posteriormente, 48 suínos (Large White x Landrace), sendo 24 machos castrados e 24 fêmeas, foram submetidos, dos 25,82 aos $92,33 \mathrm{~kg}$, a quatro tratamentos: dieta com 0\% de FG, dieta com 7\% de FG, dieta com $14 \%$ de FG e dieta com $21 \%$ de FG. Foram medidos o ganho diário de peso (GDP), o consumo diário de ração (CDR) e a conversão alimentar (CA) durante quatro períodos (crescimento I, crescimento II, terminação e período total). Finalmente, os animais foram abatidos e submetidos à tipificação eletrônica de carcaça. Foram medidos a espessura de toucinho (ET), a profundidade do músculo longissimus dorsi (PM), o peso da carcaça (PC), o rendimento da carcaça (RC), a porcentagem de carne magra na carcaça (CM) e a quantidade de carne magra na carcaça (RCM). Os valores de energia digestível e metabolizável do FG foram 2171 e $2036 \mathrm{kcal} / \mathrm{kg}$, respectivamente. Não houve efeito da regressão dos níveis de FG sobre as características de desempenho, em qualquer fase. Diferenças somente ocorreram para o fator sexo, a favor dos machos, nas fases de crescimento II e no período total para o GDP e o CDR. Para as características de carcaça não foi verificado efeito da regressão dos níveis de FG. Com relação ao sexo, entretanto, os machos apresentaram maior ET e PC. Os custos das dietas foram semelhantes entre os tratamentos. A inclusão de $21 \%$ de FG nas rações de suínos em crescimento e terminação não ofereceu prejuízo para desempenho e características de carcaça.
\end{abstract}

Palavras-chave: carcaça, desempenho, farelo de girassol, girassol, suínos

\section{Sunflower Meal to Swine on Growing and Finishing Phase: Digestibility, Performance and Carcass Quality}

\begin{abstract}
Two experiments were carried out to evaluate sunflower meal (SM) as swine feeding on growing and finishing phases. In experiment 1 , eight barrows with $30.41 \mathrm{~kg}$ liveweight were allocated in metabolic individual cages to evaluate the digestibility of sunflower meal. In experiment 2 a total of 48 pigs ( 24 barrows and 24 females), Large White x Landrace cross, were allotted to four treatments: diet without SM, diet with $7 \%$ of SM, diet with $14 \%$ of SM and diet with $21 \%$ of SM. The animals were evaluated from $25.82 \mathrm{~kg}$ to $92.33 \mathrm{~kg}$ liveweight. Daily weight gain (DWG), daily feed intake (DFI) and feed gain ratio (FGR) were evaluated during four periods (growing I, growing II, finishing and total period). All animals were slaughtered and submitted to an electronic carcass evaluation at the end of the experiment. The backfat depth (BP), muscle depth (MD), carcass weight (CW), lean meat percentage (LM), kilogram of lean meat (KLM) and carcass yield (CY) were evaluated. The digestible and metabolizable energy values of SM were 2171 and $2036 \mathrm{kcal} / \mathrm{kg}$, respectively. There were no regression effect on performance characteristics for the levels of SM. There were significant differences for sex factor. The barrows were better to DWG and DFI during the growing phase II and total period. There were no regression effect on carcass characteristics for the levels of SM however, BD and CW characteristics were significantly greater for barrows than females. The rations cost was similar among treatments. In inclusion, the rations up to $21 \%$ of SM for growing and finishing pigs, did not affect performance and carcass characteristics.
\end{abstract}

Key Words: carcass, performance, sunflower meal, sunflower, swine

\section{Introdução}

Na suinocultura brasileira são freqüentes os períodos de instabilidade principalmente em razão dos altos preços dos ingredientes que compõem as rações. Em virtude da alimentação de suínos sustentar-se basica- mente na utilização do milho e do farelo de soja, qualquer variação na composição dos custos desses produtos refletirá diretamente na margem de lucros do suinocultor (Trindade Neto et al., 1995)

A utilização de ingredientes alternativos na alimentação do suíno tem despertado interesse continu-

\footnotetext{
${ }^{1}$ Professores Doutores. Universidade Estadual de Londrina. Centro de Ciências Agrárias. Departamento de Zootecnia Caixa Postal 6001. CEP 86020-990, Londrina - PR. E.mail: casilva@uel.br

${ }^{2}$ Acadêmicos do curso de Medicina Veterinária da Universidade Estadual de Londrina.
} 
amente, quando, sob o ponto de vista nutricional e econômico, atendem os objetivos do setor.

O farelo de girassol, a princípio, apresenta-se como exemplo de um potencial ingrediente alternativo para a substituição parcial do farelo de soja nas dietas de suínos (Green \& Kiener, 1989; Hegedus \& Fekete, 1994).

Minardi (1969) citou que os valores de proteína variam de 30 a $53 \%$ para o farelo da semente de girassol descorticada e de 20 a $30 \%$ para o farelo da semente corticada. Segundo o NRC (1998), os valores de fibra bruta e de proteína bruta para o farelo de girassol são de 31,6 e $23,3 \%$, respectivamente. No processo de extração do óleo, quando a casca não é removida, o farelo contém aproximadamente $28,5 \%$ de proteína, $1,35 \%$ de extrato etéreo e $23 \%$ de fibra bruta (Embrapa, 1991).

Os elevados níveis de fibra do farelo de girassol estão relacionados diretamente com sua baixa energia digestível (Kennelly \& Aherne, 1980). Este quadro faz com que o uso do farelo de girassol deva ser limitado, sob risco de penalizar a energia final da uma ração ou de requerer mais óleo para suplementação da energia da ração, o que poderá elevar os custos finais.

Outro aspecto inerente ao farelo de girassol é a sua limitação em lisina. Os valores de lisina do farelo de girassol variam entre 0,9 e $1,5 \%$, dependendo principalmente da presença maior ou menor de casca (Seerley et al., 1974; NRC, 1998). Estes níveis são inferiores aos comumente observados no farelo de soja com $45 \%$ de proteína, que apresenta em torno de 2,65\% a 2,83\% (EMBRAPA, 1991; NRC, 1998). Não obstante, alguns trabalhos apresentaram resultados interessantes quanto ao uso do farelo de girassol para suínos em crescimento e terminação, exigindo, contudo, a suplementação de lisina para atender os requerimentos nutricionais dos animais para as fases (Seerley et al., 1974; Stothers \& Froese, 1982; Wetscherek et al., 1993; Hegedus \& Fekete, 1994).

Preservadas estas particularidades nutricionais do farelo de girassol, foi o aumento da produção desta oleaginosa, principalmente no Centro-Oeste brasileiro, mais o crescente avanço da produção suína nessa região e a escassez de informações sobre a utilização do farelo de girassol na alimentação de suínos que constituíram os motivos para a realização desse trabalho, que teve como objetivo a determinação da digestibilidade do farelo de girassol, do desempenho dos animais em crescimento e terminação submetidos a dietas com vários níveis de farelo e da qualidade da carcaça destes ao final dos tratamentos. Também foi considerado o custo benefício do uso do produto nestas fases.

R. Bras. Zootec., v.31, n.2, p.982-990, 2002 (suplemento)

\section{Material e Métodos}

Os experimentos foram realizados no setor de suinocultura da Fazenda Escola da Universidade Estadual de Londrina, no período de 23 de novembro de 2000 a 12 a fevereiro de 2001.

Para o experimento de digestibilidade foram utilizados oito leitões mestiços (Landrace x Large White), machos castrados, com peso médio inicial de 30,41 $\pm 1,42$ $\mathrm{kg}$, alojados em gaiolas metabólicas, por um período de doze dias, dos quais os sete primeiros para a adaptação dos animais às gaiolas e às rações. No oitavo dia, foram pesados para o cálculo do peso metabólico e ajuste da quantidade de ração a ser consumida.

Nos cinco dias subseqüentes, procedeu-se à coleta total de fezes e urina. Para determinar o início e o final do período de coleta, adicionou-se às rações $2 \%$ de óxido férrico $\left(\mathrm{Fe}_{2} \mathrm{O}_{3}\right.$ ) como marcador fecal.

$\mathrm{O}$ delineamento experimental utilizado foi o de blocos ao acaso, com dois tratamentos e quatro repetições. Cada repetição foi representada por um animal que foi pesado no início e no fim dessa etapa. Para a formação dos blocos levou-se em consideração o peso vivo dos animais.

Os tratamentos experimentais foram ração referência e ração teste, sendo esta última composta pela ração referência acrescida de $30 \%$ de farelo de girassol.

A ração referência foi formulada visando atender as exigências dos animais nessa fase (NCR, 1998).

Os ingredientes utilizados, a composição percentual e os valores calculados das rações teste e referência encontram-se na Tabela 1.

No manejo alimentar, as rações foram oferecidas duas vezes ao dia, às 8 e 17 h. A quantidade fornecida para cada animal foi estabelecida durante o período de adaptação.

O fornecimento de água foi definido tomando-se como base a seguinte relação: $3 \mathrm{~mL}$ de água/g de alimento consumido.

Para a coleta dos excrementos (fezes e urina) foi utilizada a metodologia de coleta total. As coletas foram realizadas duas vezes ao dia, às $6 \mathrm{~h} 30 \mathrm{e} 19 \mathrm{~h}$.

Após o período de coleta, as fezes e a urina foram preparadas e submetidas às análises laboratoriais, realizadas no Laboratório de Nutrição Animal da Universidade Estadual de Londrina.

Nas fezes e nas dietas, foram analisados os teores de matéria seca, proteína bruta, extrato etéreo, matéria mineral, fibra bruta e energia bruta. Na urina, foi analisada a energia bruta (AOAC, 1975). 
Tabela 1 - Composição percentual da ração referência Table 1 - Percent composition of basal diet

\begin{tabular}{|c|c|}
\hline $\begin{array}{l}\text { Ingredientes } \\
\text { Ingredients }\end{array}$ & $\begin{array}{l}\text { Quantidade }(\mathrm{kg}) \\
\text { Amount }\end{array}$ \\
\hline Milho & 69,420 \\
\hline Corn & \\
\hline Farelo de soja & 26,640 \\
\hline Soybean meal & \\
\hline Fosfato bicálcico & 0,825 \\
\hline Dicalcium phosphate & \\
\hline Calcário & 0,780 \\
\hline $\begin{array}{l}\text { Limestone } \\
\text { Óleo vegetal }\end{array}$ & 1,780 \\
\hline $\begin{array}{l}\text { Vegetable oil } \\
\text { L-Lisina-HCl }\end{array}$ & 0,025 \\
\hline$L$-Lysine $-\mathrm{HCl}$ & \\
\hline Colina & 0,020 \\
\hline Coline & \\
\hline $\begin{array}{l}\text { Antioxidante } \\
\text { Antioxidant }\end{array}$ & 0,010 \\
\hline $\begin{array}{l}\text { Suplemento vitamínico e mineral }{ }^{1} \\
\text { Vitamin and mineral supplement }\end{array}$ & 0,200 \\
\hline $\begin{array}{l}\text { Sal } \\
\text { Salt }\end{array}$ & 0,300 \\
\hline
\end{tabular}

Valores calculados ${ }^{2}$

Calculated values

Proteína bruta (\%)

18,000

Crude protein

Energia metabolizável (kcal/kg)

Metabolizable energy

Cálcio (\%)

3265

Calcium

Fósforo total (\%)

Total phosphorus

Lisina (\%)

Lysine

Metionina (\%)

Methionine

\begin{abstract}
${ }^{1}$ Suplemento vitamínico e mineral por kg de produto (Vitamin and mineral supplement per $\mathrm{kg}$ of product): vit.A, 3.500.000 UI; vit. $\mathrm{D}_{3}$ $500.000 \mathrm{UI}$; vit.E, $5.000 \mathrm{mg}$; vit. $\mathrm{K}_{3}, 1.000 \mathrm{mg}$; vit. $\mathrm{B}_{1}, 400 \mathrm{mg}$; vit. $B_{2}, 1.600 \mathrm{mg}$; vit. $B_{6}, 500 \mathrm{mg}$; vit. $B_{12}, 11.000 \mathrm{mcg}$; ácido fólico (folic acid), $350 \mathrm{mg}$; ácido pantotênico (pantotenic acid), $6.000 \mathrm{mg}$; niacina (niacin), $14.000 \mathrm{mg}$; biotina (biotin), $10 \mathrm{mg}$; selênio (selenium), $75 \mathrm{mg}$; antioxidante (antioxidant), $2.000 \mathrm{mg}$; Fe, $48.000 \mathrm{mg}$; Cu, $9.000 \mathrm{~g} ; \mathrm{Mg}, 30.000 \mathrm{mg} ; \mathrm{Mn}, 25.000 \mathrm{mg} ; \mathrm{Zn}$, $48.000 \mathrm{mg}$; Co, $125 \mathrm{mg}$; I, $125 \mathrm{mg}$; Se, $75 \mathrm{mg}$;

2 Valores calculados segundo Embrapa (1991) (Calculated composition according to Embrapa [1991]).
\end{abstract}

Para os cálculos de digestibilidade foi empregado o método de Matterson et al. (1965).

Calcularam-se os valores dos coeficientes de digestibilidade da matéria seca, da proteína bruta e da energia bruta, o que possibilitou o cálculo da matéria seca digestível, da proteína digestível e da energia digestível. Finalmente, o coeficiente de metabolizibilidade da energia digestível permitiu a obtenção da energia metabolizável do farelo de girassol.

Para a avaliação do desempenho nas fases de crescimento e terminação, foram utilizados 48 animais, sendo 24 machos castrados e 24 fêmeas, mestiços (Large White $\mathrm{x}$ Landrace), com peso médio inicial de $25,82 \pm 1,12 \mathrm{~kg}$ e idade média de $63 \pm 2,55$ dias.

Os animais foram alojados em número de dois do mesmo sexo em baias de alvenaria com piso compacto e área de $3 \mathrm{~m}^{2}$, onde receberam água e ração à vontade, durante todo o período experimental.

Os animais foram aleatoriamente distribuídos, formando quatro grupos que receberam os seguintes tratamentos:

$\mathrm{T}_{1}$ - tratamento testemunha com $0 \%$ de farelo de girassol na ração.

$\mathrm{T}_{2}$ - tratamento com $7 \%$ de inclusão de farelo de girassol na ração.

$\mathrm{T}_{3}$ - tratamento com $14 \%$ de inclusão de farelo de girassol na ração.

$\mathrm{T}_{4}$ - tratamento com $21 \%$ de inclusão de farelo de girassol na ração.

As rações foram formuladas visando atender as exigências estabelecidas pelo NRC (1998), subdividindo as necessidades nutricionais dos animais para três faixas de peso, entre 20 e $50 \mathrm{~kg}$ de peso vivo (crescimento I), entre 50 e $80 \mathrm{~kg}$ de peso vivo (crescimento II) e entre 80 e $120 \mathrm{~kg}$ de peso vivo (terminação).

$\mathrm{Na}$ formulação das dietas experimentais, foram utilizados os valores da energia metabolizável, obtida no ensaio de digestibilidade do farelo de girassol, e os valores de proteína bruta, de fibra bruta, de cálcio e de fósforo total obtidos nas análises bromatológicas do farelo de girassol.

As rações eram isoenergéticas, isoprotéicas, isolisínicas e com semelhantes níveis de cálcio e fósforo total (Tabela 2).

Para verificar a viabilidade econômica da utilização do farelo de girassol nas rações de crescimento e terminação, foi determinado o custo médio em ração por quilograma de peso vivo $(\mathrm{Y} i)$, durante o período experimental, conforme Bellaver et al. (1985):

$$
Y i=\frac{\mathrm{Q} i \mathrm{x} \mathrm{P} i}{\mathrm{G} i},
$$

em que: $\mathrm{Y} i=$ custo médio em ração por quilograma ganho no $i$-ésimo tratamento; $\mathrm{P} i=$ preço médio por quilograma da ração utilizada no $i$-ésimo tratamento; $\mathrm{Q} i=$ quantidade média de ração consumida no 
Tabela 2 - Composição percentual e calculada das rações experimentais para avaliação de desempenho Table 2 - Percentage and calculed composition of the experimental diets for performance evaluation

\begin{tabular}{|c|c|c|c|c|c|c|c|c|c|c|c|c|}
\hline \multirow[t]{2}{*}{$\begin{array}{l}\text { Ingredientes } \\
\text { Ingredients }\end{array}$} & \multicolumn{4}{|c|}{$\begin{array}{l}\text { Fase de crescimento I } \\
\text { Growing phase I }\end{array}$} & \multicolumn{4}{|c|}{$\begin{array}{c}\text { Fase de crescimento II } \\
\text { Growing phase II }\end{array}$} & \multicolumn{4}{|c|}{$\begin{array}{l}\text { Fase de terminação } \\
\text { Finishing phase }\end{array}$} \\
\hline & $\mathrm{T}_{1}$ & $\mathrm{~T}_{2}$ & $\mathrm{~T}_{3}$ & $\mathrm{~T}_{4}$ & $\mathrm{~T}_{1}$ & $\mathrm{~T}_{2}$ & $\mathrm{~T}_{3}$ & $\mathrm{~T}_{4}$ & $\mathrm{~T}_{1}$ & $\mathrm{~T}_{2}$ & $\mathrm{~T}_{3}$ & $\mathrm{~T}_{4}$ \\
\hline $\begin{array}{l}\text { Milho } \\
\text { Corn }\end{array}$ & 69,11 & 63,89 & 58,73 & 53,58 & 76,78 & 71,57 & 66,39 & 61,24 & 83,65 & 78,44 & 73,28 & 68,08 \\
\hline $\begin{array}{l}\text { Farelo de soja } \\
\text { Soybean meal }\end{array}$ & 26,55 & 22,87 & 19,13 & 15,42 & 19,58 & 15,89 & 12,19 & 8,46 & 13,10 & 9,42 & 5,70 & 1,98 \\
\hline $\begin{array}{l}\text { Farelo de girassol } \\
\text { Sunflower meal }\end{array}$ & 0,00 & 7,00 & 14,00 & 21,00 & 0,00 & 7,00 & 14,00 & 21,00 & 0,00 & 7,00 & 14,00 & 21,00 \\
\hline $\begin{array}{l}\text { Fosfato bicálcico } \\
\text { Dicalcium phosphate }\end{array}$ & 0,84 & 0,82 & 0,81 & 0.79 & 0,68 & 0,67 & 0,65 & 0,64 & 0,52 & 0,50 & 0,49 & 0,47 \\
\hline $\begin{array}{l}\text { Calcário } \\
\text { Limestone }\end{array}$ & 0,85 & 0,82 & 0,79 & 0,75 & 0,73 & 0,70 & 0,66 & 0,63 & 0,76 & 0,73 & 0,69 & 0,66 \\
\hline $\begin{array}{l}\text { L-Lisina-HCl } \\
\text { L-Lysine- } \mathrm{HCl}\end{array}$ & 0,10 & 0,16 & 0,23 & 0,29 & 0,06 & 0,12 & 0,18 & 0,24 & 0,07 & 0,13 & 0,19 & 0,25 \\
\hline $\begin{array}{l}\text { Óleo vegetal } \\
\text { Vegetal oil }\end{array}$ & 1,85 & 3,74 & 5,61 & 7,47 & 1,47 & 3,35 & 5,23 & 7,09 & 1,20 & 3,08 & 4,95 & 6,82 \\
\hline $\begin{array}{l}\text { Suplemento vitamínico } \\
\text { Vitamin supplement }\end{array}$ & 0,40 & 0,40 & 0,40 & 0,40 & 0,40 & 0,40 & 0,40 & 0,40 & 0,40 & 0,40 & 0,40 & 0,40 \\
\hline $\begin{array}{l}\text { Suplemento mineral } \\
\text { Mineral supplement }\end{array}$ & 0,05 & 0,05 & 0,05 & 0,05 & 0,05 & 0,05 & 0,05 & 0,05 & 0,05 & 0,05 & 0,05 & 0,05 \\
\hline $\begin{array}{l}\text { Sal } \\
\text { Salt }\end{array}$ & 0,25 & 0,25 & 0,25 & 0,25 & 0,25 & 0,25 & 0,25 & 0,25 & 0,25 & 0,25 & 0,25 & 0,25 \\
\hline
\end{tabular}

Valor calculado 4

Calculated values

\begin{tabular}{|c|c|c|c|c|c|c|c|c|c|c|c|c|}
\hline $\begin{array}{l}\text { Proteína bruta (\%) } \\
\text { Crude protein }\end{array}$ & 18,00 & 18,00 & 18,00 & 18,00 & 15,50 & 15,50 & 15,50 & 15,50 & 13,20 & 13,20 & 13,20 & 13,20 \\
\hline $\begin{array}{l}\mathrm{EM}(\mathrm{kcal} / \mathrm{kg}) \\
M E\end{array}$ & 3270 & 3270 & 3270 & 3270 & 3270 & 3270 & 3270 & 3270 & 3270 & 3270 & 3270 & 3270 \\
\hline $\begin{array}{l}\text { Fibra bruta }(\%) \\
\text { Crude fiber }\end{array}$ & 2,98 & 4,72 & 6,47 & 8,21 & 2,76 & 4,50 & 6,25 & 7,99 & 2,55 & 4,29 & 6,03 & 7,78 \\
\hline $\begin{array}{l}\text { Metionina (\%) } \\
\text { Methionine }\end{array}$ & 0,28 & 0,25 & 0,25 & 0,25 & 0,24 & 0,21 & 0,20 & 0,20 & 0,21 & 0,18 & 0,17 & 0,17 \\
\hline $\begin{array}{l}\text { Lisina }(\%) \\
\text { Lysine }\end{array}$ & 0,95 & 0,95 & 0,95 & 0,95 & 0,75 & 0,75 & 0,75 & 0,75 & 0,60 & 0,60 & 0,60 & 0,60 \\
\hline $\begin{array}{l}\text { Cálcio }(\%) \\
\text { Calcium }\end{array}$ & 0,60 & 0,60 & 0,60 & 0,60 & 0,50 & 0,50 & 0,50 & 0,50 & 0,45 & 0,45 & 0,45 & 0,45 \\
\hline $\begin{array}{l}\text { Fósforo total (\%) } \\
\text { Total phosphorus }\end{array}$ & 0,50 & 0,50 & 0,50 & 0,50 & 0,45 & 0,45 & 0,45 & 0,45 & 0,40 & 0,40 & 0,40 & 0,40 \\
\hline
\end{tabular}

\footnotetext{
${ }^{1}$ Suplemento vitamínico crescimento por kg de produto (Growth vitamin supplement per $\mathrm{kg}$ of product): vit.A, 1.000.000 UI; vit. $\mathrm{D}_{3} 250.000 \mathrm{UI}$; vit.E, $2.750 \mathrm{Ul}$; vit. $\mathrm{K}_{3}, 625 \mathrm{mg}$; vit. $\mathrm{B}_{1}, 300 \mathrm{mg}$; vit. $\mathrm{B}_{2}, 1.050 \mathrm{mg}$; vit. $\mathrm{B}_{6}, 275 \mathrm{mg}$; vit. $\mathrm{B}_{12}, 3.750 \mathrm{mcg}$; ácido fólico (folic acid), $150 \mathrm{mg}$; ácido pantotenico (pantotenic acid), $3.500 \mathrm{mg}$; niacina (niacin), $5.750 \mathrm{mg}$; colina (choline), $25.000 \mathrm{mg}$; selênio (selenium), $75 \mathrm{mg}$; promotor de crescimento (growth promoter), 7,5g; antioxidante (antoxidant), $2,5 \mathrm{~g}$.

${ }^{2}$ Premix vitamínico terminação por kg de produto (Finishing vitamin mix per kg of product): vit.A, $550.000 \mathrm{UI}$; vit. $\mathrm{D}_{3} 150.000 \mathrm{UI}$; vit. E, $2.500 \mathrm{UI}$ vit. $\mathrm{K}_{3}, 550 \mathrm{mg}$; vit. $\mathrm{B}_{1}, 175 \mathrm{mg}$; vit. $\mathrm{B}_{2}, 900 \mathrm{mg}$; vit; vit. $\mathrm{B}_{12}, 3.000 \mathrm{mcg}$; ácido fólico (folic acid), $150 \mathrm{mg}$; ácido pantotenico (pantotenic acid), $3.000 \mathrm{mg}$; niacina (niacin), $4.750 \mathrm{mg}$; selênio (selenium), $75 \mathrm{mg}$; promotor de crescimento (growth promoter), 6,25g; antioxidante (antoxidant), $2,5 \mathrm{~g}$.

${ }^{3}$ Premix mineral por kg de produto (Mineral mix per kg of product): Fe, 90.000mg; Cu, 16.000g; Mg, 30.000 mg; Zn, 140.000 mg; Co, 200 mg; I, $850 \mathrm{mg}$; Se, $120 \mathrm{mg}$.

4 Valores calculados segundo Embrapa (1991) (Calculed composition according Embrapa [1991]).
} 
$i$-ésimo tratamento; $\mathrm{G} i=$ ganho médio de peso do $i$-ésimo tratamento.

Na seqüência, calculou-se o Índice de Eficiência Econômica (IEE) e o Índice de Custo Médio (IC), propostos por Barbosa et al. (1992).

$\mathrm{IEE}=\frac{\mathrm{MCe}}{\mathrm{CTe} i} \times 100$ e IC $=\frac{\mathrm{CTe} i}{\mathrm{MCe}} \times 100$,

em que: $\mathrm{MCe}=$ menor custo médio observado em ração por quilograma de peso vivo ganho entre os tratamentos; CTe $i=$ custo médio do tratamento $i$ considerado.

Os valores (preços $/ \mathrm{kg}$ ) dos ingredientes utilizados na elaboração dos custos foram obtidos na região de Londrina, no mês de março de 2001, sendo: calcário ( $\mathrm{R} \$ 0,065)$, DL-metionina ( $\mathrm{R}$ \$ 6,50), farelo de soja $(\mathrm{R} \$ 0,395)$, farelo de girassol $(\mathrm{R} \$ 0,145)$, fosfato bicálcico ( $\mathrm{R} \$ 0,60)$, L-lisina ( $\mathrm{R}$ 4,20), milho ( $R$ \$ 0,14), óleo ( $R$ \$ 0,65), sal comum ( $\mathrm{R} \$ 0,12)$, suplemento vitamínico crescimento ( $\mathrm{R} \$ 2,195)$, suplemento vitamínico terminação $(\mathrm{R} \$ 1,875)$ e suplemento mineral $(\mathrm{R} \$ 2,385)$

O delineamento experimental foi inteiramente casualizado, num modelo fatorial $4 \times 2$, sendo quatro tratamentos e dois sexos, com três repetições por tratamento.

Ao final do experimento de desempenho, os animais foram encaminhados ao Frigorífico Frimesa, localizado no município de Medianeira, Paraná, sendo abatidos e submetidos à avaliação das características de carcaça.

As carcaças foram individualmente avaliadas com o auxílio de uma pistola tipificadora Stork-SFK (modelo S87), utilizando o sistema informatizado "Fato-MEATER FOM". A pistola foi introduzida na altu-

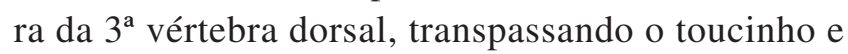
o músculo longissimus dorsi.

Os dados obtidos foram: espessura de toucinho, profundidade do músculo longissimus dorsi, peso da carcaça quente, rendimento da carcaça, porcentagem de carne magra na carcaça e quilograma de carne magra na carcaça. Cada animal foi considerado uma repetição. Portanto, mantido o delineamento inicial, o modelo fatorial foi $4 \times 2$ (quatro tratamentos e dois sexos), com seis repetições por tratamento.

Os dados relativos aos tratamentos foram submetidos a análise de regressão polinomial e os dados relacionados ao sexo foram avaliados através da análise de variância e ao teste de Tukey, utilizando-se o programa SAEG (UFV, 1997).

\section{Resultados e Discussão}

Os resultados do ensaio de digestibilidade, representados pelos valores de energia bruta, digestível e metabolizável, matéria seca e proteína bruta digestível do farelo de girassol e respectivos coeficientes de digestibilidade e metabolizibilidade estão demonstrados na Tabela 3.

O coeficiente de digestibilidade da proteína e da matéria seca do farelo de girassol foi semelhante aos resultados obtidos por Lima et al. (1989) que, trabalhando com diferentes granulometrias, verificaram 72,43 e 73,24\% de digestibilidade da proteína e 44,38 e $54,04 \%$ de digestibilidade da matéria seca para os farelos grosso e fino, respectivamente.

Os resultados do coeficiente de digestibilidade da matéria seca estão relacionados com o nível de fibra do produto. Jongbloed et al. ( 1992 ), trabalhando com o farelo de girassol com 19, 23, 29 e 35\% de fibra bruta, obtiveram, respectivamente, um coeficiente de digestibilidade de 62,$9 ; 60,5 ; 57,6$; e 44,8\%.

Quanto aos valores de proteína digestível, Lima et al. (1989), utilizando dois tipos de granulometria para o farelo de girassol, obtiveram valores de proteína digestível de 20,82\% (farelo grosso) e 21,05\% (farelo fino). Segundo a Embrapa (1991), a proteína digestível

Tabela 3 - Valores de energia bruta, digestível e metabolizável, matéria seca e proteína bruta digestível do farelo de girassol e respectivos coeficientes de digestibilidade e metabolizibilidade aparentes

Table 3 - Values of crude, digestible and metabolizable energy, dry matter and crude protein digestible of sunflower meal and respectives coefficients of apparent digestibility and metabolizibility

\begin{tabular}{lcc}
\hline $\begin{array}{l}\text { Farelo de girassol } \\
\text { Sunflower meal }\end{array}$ & $\begin{array}{c}\text { Valores } \\
\text { Values }\end{array}$ & $\begin{array}{c}\text { Coeficientes } \\
\text { Coefficients }\end{array}$ \\
\hline $\begin{array}{l}\text { Matéria seca digestível } \\
\text { Digestible dry matter }\end{array}$ & $51,62 \%$ & $56,57^{1 \%}$ \\
$\begin{array}{l}\text { Proteína digestível } \\
\text { Digetible protein }\end{array}$ & $21,58 \%$ & $73,82^{1} \%$ \\
$\begin{array}{l}\text { Energia bruta } \\
\text { Gross energy }\end{array}$ & $4191 \mathrm{kcal} / \mathrm{kg}$ & \\
$\begin{array}{l}\text { Energia digestível } \\
\text { Digestible energy }\end{array}$ & $2171 \mathrm{kcal} / \mathrm{kg}$ & $51,801 \%$ \\
$\begin{array}{l}\text { Energia metabolizável } \\
\text { Metabolizable energy }\end{array}$ & $2036 \mathrm{kcal} / \mathrm{kg}$ & $48,58^{2} \%$ \\
\hline
\end{tabular}

\footnotetext{
${ }^{1}$ Coeficiente de digestiblilidade.

${ }^{2}$ Coeficiente de metabolizibilidade.

1 Coefficient of digestibility.

${ }^{2}$ Coefficient of metabolizibility.
} 
encontrada no farelo de girassol com casca foi de $21,02 \%$.

Os resultados da energia digestível observados por Lima et al. (1989) foram de 1851 e $2151 \mathrm{kcal} / \mathrm{kg}$ de ração para o farelo grosso e fino, respectivamente. Comparando os resultados de energia digestível com os valores apresentados pela Embrapa (1991) e pelo NRC (1998), respectivamente, 1763 e 2010 kcal/kg, observou-se que o valor obtido encontra-se dentro dos limites citados.

Para a energia metabolizável, valores inferiores foram observados por Lima et al. (1989) e NRC (1998), que foram 1519 e $1830 \mathrm{kcal} / \mathrm{kg}$, respectivamente.

Os resultados, de maneira geral, apontam que os níveis maiores de fibra no farelo de girassol pioram a digestibilidade dos nutrientes. O comportamento do aproveitamento dos nutrientes também é semelhante quando o farelo recebe algum tipo de tratamento. Szelenyi et al. (1994) notaram que, com o uso do farelo de girassol sem tratamento (somente triturado), o coeficiente de digestibilidade da proteína foi de $80,6 \%$ e da energia, de $97,7 \%$. Com a extrusão do farelo de girassol, esses valores passaram a ser de 84,5 e $97,9 \%$, respectivamente.

Os resultados do desempenho zootécnico obtidos com os quatro níveis de farelo de girassol avaliados estão apresentados nas Tabelas 4, 5, 6 e 7.

Não foi observado efeito significativo $(\mathrm{P}>0,05)$ para os níveis de farelo utilizado, indicando que, independentemente da fase (crescimento I, crescimento II, terminação ou total), para todas as variáveis analisadas, a inclusão de até $21 \%$ de farelo de girassol não influenciou o desempenho dos animais.

Ao se observarem os valores de conversão alimentar para a fase de crescimento I, verificou-se que, embora não exista diferença $(\mathrm{P}>0,05)$ entre os tratamentos, tendência de piora no parâmetro aparece para os níveis mais elevados de inclusão do farelo de girassol. Presume-se que este comportamento nesta primeira fase esteja relacionado com a idade dos animais (animais jovens) e, possivelmente, pela falta de adaptação do trato digestivo aos mais elevados níveis de fibra nas dietas com farelo de girassol. Em contrapartida, o aumento de inclusão de óleo nas rações com mais farelo de girassol vem equilibrar este aumento de fibra pela melhora que este ingrediente exerce na digestibildade dos demais nutrientes da dieta.

As diferenças observadas no experimento de desempenho somente foram significativas $(\mathrm{P}<0,05)$ para as variáveis ganho diário de peso e consumo
Tabela 4 - Efeito dos diferentes níveis do farelo de girassol sobre o ganho diário de peso (GDP), consumo diário de ração (CDR) e conversão alimentar (CA) na fase de crescimento I

Table 4 - Effect of different levels of sunflower meal on daily weight gain (DWG), daily feed intake (DFI) and feed gain ratio $(F G)$ in the growing phase I

\begin{tabular}{lccc}
\hline $\begin{array}{l}\text { Tratamentos } \\
\text { Treatments }\end{array}$ & \multicolumn{3}{c}{$\begin{array}{c}\text { Fatores } \\
\text { Factors }\end{array}$} \\
\cline { 2 - 4 } & GDP $(\mathrm{g})$ & CDR $(\mathrm{g})$ & $\mathrm{CA}$ \\
& $D W G(g)$ & $D F I(g)$ & $F G$ \\
\hline $0 \%$ & 846 & 2264 & 2,69 \\
$7 \%$ & 747 & 2097 & 2,81 \\
$14 \%$ & 785 & 2109 & 2,71 \\
$21 \%$ & 803 & 2263 & 2,85 \\
Sexo & & & \\
Sex & & & \\
Machos castrados & $811 \mathrm{x}$ & $2193 \mathrm{x}$ & $2,73 \mathrm{x}$ \\
Barrows & & & \\
Fêmeas & $779 \mathrm{x}$ & $2172 \mathrm{x}$ & $2,81 \mathrm{x}$ \\
Females & & & \\
CV $(\%)$ & 11,59 & 7,19 & 10,32 \\
\hline
\end{tabular}

Médias seguidas de mesma letra para sexos, na mesma coluna, não diferem $(P>0,05)$ pelo teste de Tukey.

Means of sexes, within the same column, followed by same letter, did not differ $(P>.05)$ by Tukey test.

diário de ração, entre os sexos estudados, a favor dos machos na fase de crescimento II e no período total do experimento.

Os trabalhos conduzidos com o farelo de girassol na alimentação de suínos devem considerar as características do produto, pois, além dos elevados níveis de fibra bruta e baixa energia metabolizável em relação ao milho e à soja, apresentam deficiência de lisina, entretanto é rico em outros aminoácidos essenciais, principalmente os sulfurados (NRC, 1998).

Visando otimizar o uso do farelo de girassol, Seerley et al. (1974) obtiveram resultados interessantes com o produto em substituição ao farelo de soja. Sem a suplementação de lisina, os resultados com a substituição de 50 ou $100 \%$ da proteína da soja foram negativos para o ganho de peso, entretanto, para $25 \%$ de substituição não foi observada depressão no ganho de peso, porém houve piora na conversão alimentar $(3,30$ vs 3,61). Atendida a deficiência de lisina, pela suplementação com $0,3 \%$ do aminoácido, os resultados de desempenho foram melhorados e as principais características de carcaça apresentaram-se semelhantes, quando 25 e $50 \%$ do farelo de girassol substituiu a proteína de soja nas dietas.

Utilizando leitões com 17,0 a 37,5 kg de peso vivo, Stothers \& Froese (1982) realizaram um experimento substituindo o farelo de soja integralmente pelo farelo 
Tabela 5 - Efeito dos diferentes níveis do farelo de girassol sobre o ganho diário de peso (GDP), consumo diário de ração (CDR) e conversão alimentar (CA) na fase de crescimento II

Table 5 - Effect of different levels of sunflower meal on daily weight gain (DWG), daily feed intake (DFI) and feed gain ratio $(F G)$ in the growing phase II

\begin{tabular}{lccc}
\hline $\begin{array}{l}\text { Tratamentos } \\
\text { Treatments }\end{array}$ & \multicolumn{3}{c}{$\begin{array}{c}\text { Fatores } \\
\text { Factors }\end{array}$} \\
\cline { 2 - 4 } & GDP $(\mathrm{g})$ & $\mathrm{CDR}(\mathrm{g})$ & $\mathrm{CA}$ \\
& $D W G(\mathrm{~g})$ & $D F I(g)$ & $F G$ \\
\hline $0 \%$ & 803 & 2491 & 3,19 \\
$7 \%$ & 806 & 2549 & 3,17 \\
$14 \%$ & 793 & 2436 & 3,08 \\
$21 \%$ & 822 & 2407 & 2,95 \\
Sexo & & & \\
Sex & & & \\
Machos castrados & $855 \mathrm{x}$ & $2601 \mathrm{x}$ & $3,06 \mathrm{x}$ \\
Barrows & & & \\
Fêmeas & $757 \mathrm{y}$ & $2340 \mathrm{y}$ & $3,13 \mathrm{x}$ \\
Females & & & \\
CV $(\%)$ & 11,96 & 9,40 & 8,95 \\
\hline
\end{tabular}

Médias seguidas de letras diferentes para sexos $(x, y)$, na mesma coluna, diferem $(\mathrm{P}<0,05)$ pelo teste de Tukey.

Means of sexes, within the same column, followed by different letters $(x, y)$, differ $(P<.05)$ by Tukey test.

de girassol sem casca (42\% de proteína bruta) suplementado com dois níveis de lisina $(0,14$ e $0,16 \%)$. Todas as rações eram isocalóricas e isoprotéicas ( $16 \%$ de proteína bruta). Os resultados indicaram maior consumo para o grupo controle (dieta com farelo de soja), o ganho de peso, porém foi maior para os grupos controle e teste com $0,16 \%$ de lisina $(\mathrm{P}<0,05)$. Para o ganho de peso e para a conversão alimentar, os resultados para os grupos controle, teste com $0,14 \%$ de lisina e teste com $0,16 \%$ de lisina, foram, respectivamente, $610 \mathrm{~g}, 2,62 ; 550 \mathrm{~g}, 2,62$; e $590 \mathrm{~g}$ e 2,52.

Suínos em crescimento e terminação alimentados com dietas contendo $0,9,18$ e $27 \%$ de farelo de girassol descorticado em substituição ao farelo de soja, apresentaram até os $60 \mathrm{~kg}$ de peso vivo um desempenho reduzido quando o farelo de girassol participou da formulação, porém sem a suplementação de lisina. Todavia, entre 60 e $100 \mathrm{~kg}$ de peso vivo, não foi verificada diferença $(\mathrm{P}>0,05)$ entre os tratamentos mesmo sem a suplementação de lisina (Wetscherek et al., 1993).

Hegedus \& Fekete (1994) confirmaram esta proposição ao concluírem que o farelo de girassol pode substituir o farelo de soja, desde que a energia da dieta seja mantida e a lisina seja suplementada.

Na Tabela 8 estão registrados os dados de
Tabela 6 - Efeito dos diferentes níveis do farelo de girassol sobre o ganho diário de peso (GDP), consumo diário de ração (CDR) e conversão alimentar (CA) na fase de terminação

Table 6 - Effect of different levels of sunflower meal on daily weight gain (DWG), daily feed intake (DFI) and feed gain ratio $(F G)$ in the finishing phase

\begin{tabular}{lccc}
\hline $\begin{array}{l}\text { Tratamentos } \\
\text { Treatments }\end{array}$ & \multicolumn{3}{c}{$\begin{array}{c}\text { Fatores } \\
\text { Factors }\end{array}$} \\
\cline { 2 - 4 } & GDP $(\mathrm{g})$ & CDR $(\mathrm{g})$ & $\mathrm{CA}$ \\
& $D W G(g)$ & $D F I(g)$ & $F G$ \\
\hline $0 \%$ & 936 & 3706 & 4,03 \\
$7 \%$ & 959 & 3721 & 3,93 \\
$14 \%$ & 925 & 3716 & 4,06 \\
$21 \%$ & 967 & 3647 & 3,79 \\
Sexo & & & \\
Sex & $1005 \mathrm{x}$ & $3847 \mathrm{x}$ & $3,85 \mathrm{x}$ \\
Machos castrados & & & \\
Barrows & $889 \mathrm{x}$ & $3547 \mathrm{x}$ & $4,06 \mathrm{x}$ \\
Fêmeas & & & \\
Females & 16,27 & 12,63 & 15,60 \\
CV $(\%)$ &
\end{tabular}

Médias seguidas de mesma letra para sexos, na mesma coluna, não diferem $(P>0,05)$ pelo teste de Tukey.

Means of sexes, within the same column, followed by same letter, did not differ $(P>.05)$ by Tukey test.

carcaça dos animais submetidos aos tratamentos.

Não foram observados efeitos significativos ( $\mathrm{P}>0,05)$, em função dos níveis do farelo de girassol nas rações, sobre as características de carcaça.

Tabela 7 - Efeito dos diferentes níveis do farelo de girassol sobre o ganho diário de peso (GDP), consumo diário de ração (CDR) e conversão alimentar (CA) no período total

Table 7 - Effect of different levels of sunflower meal on daily weight gain (DWG), daily feed intake (DFI) and feed gain ratio (FG) in the total period

\begin{tabular}{lccc}
\hline $\begin{array}{l}\text { Tratamentos } \\
\text { Treatments }\end{array}$ & \multicolumn{3}{c}{$\begin{array}{c}\text { Fatores } \\
\text { Factors }\end{array}$} \\
\cline { 2 - 4 } & GDP $(\mathrm{g})$ & $\mathrm{CDR}(\mathrm{g})$ & $\mathrm{CA}$ \\
& $D W G(\mathrm{~g})$ & $D F I(g)$ & $F G$ \\
\hline $0 \%$ & 832 & 2622 & 3,16 \\
$7 \%$ & 812 & 2595 & 3,20 \\
$14 \%$ & 813 & 2544 & 3,14 \\
$21 \%$ & 839 & 2571 & 3,08 \\
Sexo & & & \\
Sex & & & \\
Machos castrados & $865 \mathrm{x}$ & $2675 \mathrm{x}$ & $3,10 \mathrm{x}$ \\
Barrows & $783 \mathrm{y}$ & $2491 \mathrm{y}$ & $3,19 \mathrm{x}$ \\
Fêmeas & & & \\
Females & 11,05 & 8,22 & 7,69 \\
CV $(\%)$ &
\end{tabular}

Médias seguidas de letras diferentes para sexos $(x, y)$, na mesma coluna, diferem $(\mathrm{P}<0,05)$ pelo teste de Tukey.

Means of sexes, within the same column, followed by different letters $(x, y)$, differ $(P<.05)$ by Tukey test.

\section{R. Bras. Zootec., v.31, n.2, p.982-990, 2002 (suplemento)}


Estes dados indicaram que a inclusão de $21 \%$ de farelo de girassol na dieta para animais em crescimento e terminação não resultou em alterações nos parâmetros avaliados.

Szabo et al. (1999), trabalhando com quatro diferentes fontes protéicas nas dietas de leitões entre 30 e $105 \mathrm{~kg}$ de peso vivo (farelo de soja, farelo de girassol, farelo de ervilha e farinha de carne), também não observaram diferenças entre os tratamentos para os parâmetros de desempenho, para a porcentagem de carne magra e para as características qualitativas da carne (conteúdo de gordura intramuscular, $\mathrm{pH}$ da carne 24 horas pós-abate, perda de água da carcaça e cor da carne).

Quanto ao fator sexo, as variáveis espessura de toucinho e peso da carcaça foram maiores $(\mathrm{P}<0,05)$ para os machos castrados. Este quadro em grande parte se explica pelo potencial que a categoria tem para depositar gordura, normalmente relacionado com o maior consumo de ração.
Os parâmetros porcentagem de carne magra e profundidade do músculo favoreceram as fêmeas $(\mathrm{P}<0,05)$. Este comportamento indica uma relação inversamente proporcional entre o tecido magro e a deposição muscular sobre a deposição de gordura.

$\mathrm{O}$ peso da carcaça dos machos foi maior que das fêmeas $(\mathrm{P}<0,05)$, entretanto, devido ao percentual de carne magra ser maior para as fêmeas, as variáveis quilograma de carne magra e rendimento de carcaça apresentaram-se semelhantes entre os sexos $(\mathrm{P}>0,05)$.

Na Tabela 9 estão apresentados os índices de custo, de eficiência econômica e de custo médio em ração por quilograma de peso vivo ganho para os quatro tratamentos utilizados.

É possível indicar que a melhor dieta em termos de índice de eficiência econômica e de custo foi o tratamento testemunha, seguida pelos níveis de 7 e 14 e $21 \%$, respectivamente.

Tabela 8 - Efeito dos diferentes níveis do farelo de girassol sobre a espessura de toucinho (ET), profundidade do músculo $(P M)$, peso da carcaça $(P C)$, porcentagem de carne magra $(C M)$, quilo de carne magra $(K C M)$ e rendimento de carcaça $(\mathrm{RC})$

Table 8 - Effects of different levels of sunflower meal on backfat depth (BD), muscle depth (MD), carcass weight (CW), lean meat percent (LM), kilogram of lean meat (KLM) and carcass yield (CY)

\begin{tabular}{|c|c|c|c|c|c|c|}
\hline \multirow[t]{2}{*}{$\begin{array}{l}\text { Tratamentos } \\
\text { Treatments }\end{array}$} & \multicolumn{6}{|c|}{$\begin{array}{l}\text { Fatores } \\
\text { Factors }\end{array}$} \\
\hline & $\begin{array}{c}\mathrm{ET}(\mathrm{mm}) \\
B D\end{array}$ & $\begin{array}{c}\mathrm{PM}(\mathrm{mm}) \\
M D\end{array}$ & $\begin{array}{c}\mathrm{PC}(\mathrm{kg}) \\
C W\end{array}$ & $\begin{array}{c}\mathrm{CM}(\%) \\
L M\end{array}$ & $\begin{array}{c}\mathrm{KCM}(\mathrm{kg}) \\
K L M\end{array}$ & $\begin{array}{c}\mathrm{RC}(\%) \\
C Y\end{array}$ \\
\hline $0 \%$ & 17,75 & 50,91 & 61,95 & 53,24 & 32,89 & 66,80 \\
\hline $7 \%$ & 18,83 & 49,00 & 62,17 & 52,38 & 32,45 & 67,66 \\
\hline $14 \%$ & 16,66 & 51,66 & 61,87 & 54,07 & 33,34 & 67,09 \\
\hline $21 \%$ & 17,50 & 51,92 & 63,63 & 53,54 & 33,84 & 67,80 \\
\hline \multicolumn{7}{|l|}{ Sexo } \\
\hline \multicolumn{7}{|l|}{ Sex } \\
\hline Castrados & $20,67 x$ & $48,17 y$ & $64,40 x$ & $50,98 y$ & $32,74 x$ & $67,56 x$ \\
\hline $\begin{array}{l}\text { Barrows } \\
\text { Fêmeas }\end{array}$ & $14,70 y$ & $53,58 x$ & $60,39 y$ & $55,63 x$ & $33,52 x$ & $67,11 x$ \\
\hline Females & & & & & & \\
\hline CV $(\%)$ & & & & & & \\
\hline
\end{tabular}

Médias seguidas de letras diferentes para sexos $(x, y)$, na mesma coluna, diferem $(P<0,05)$ pelo teste de Tukey.

Means of sexes, within the same column, followed by different letters $(x, y)$, differ $(P<.05)$ by Tukey test. 
Tabela 9 - Custo médio em ração por quilograma de peso vivo ganho, índice médio de custo e índice de eficiência econômica de leitões (63 - 144 dias), de acordo com os níveis de inclusão de farelo de girassol

Table 9 - Ration cost per gain of body weight $(\mathrm{kg})$, average cost rate and rate of efficience economic for pigs (63 - 144 days), according to the levels of sunflower

\begin{tabular}{|c|c|c|c|c|}
\hline \multirow[t]{2}{*}{$\begin{array}{l}\text { Parâmetros } \\
\text { Parameters }\end{array}$} & \multicolumn{4}{|c|}{$\begin{array}{l}\text { Níveis de farelo de } \\
\text { girassol (\%) } \\
\text { Sunflower meal levels }\end{array}$} \\
\hline & 0 & 7 & 14 & 21 \\
\hline Custo em ração ( $\mathrm{R} \$ / \mathrm{kg})$ & 0,665 & 0,687 & 0,690 & 0,690 \\
\hline $\begin{array}{l}\text { Ration cost } \\
\text { Índice de custo } \\
\text { Cost ratio }\end{array}$ & 100 & 103,16 & 103,62 & 103,62 \\
\hline $\begin{array}{l}\text { Índice de eficiência } \\
\text { econômica } \\
\text { Economic efficience rate }\end{array}$ & 100 & 96,92 & 96,50 & 96,50 \\
\hline
\end{tabular}

\section{Conclusões}

Os valores de energia digestível e metabolizável do farelo de girassol foram de 2171 e $2036 \mathrm{kcal} / \mathrm{kg}$, respectivamente.

A inclusão de até $21 \%$ de farelo de girassol nas dietas de leitões em crescimento e terminação, em substituição parcial ao milho e ao farelo de soja, não influenciou as características de desempenho e de carcaça.

Os índices de custos foram, de acordo com os valores estimados dos ingredientes, favoráveis para a dieta com $0 \%$ de inclusão de girassol.

O farelo de girassol, preservadas as condições de preço dos ingredientes utilizados, pode ser incluído em até $21 \%$ nas rações de suínos em crescimento e terminação.

\section{Agradecimento}

À CARAMURU ALIMENTOS Ltda., pelo fornecimento do farelo de girassol e pelo apoio para a realização das análises laboratoriais.

\section{Literatura Citada}

ASSOCIATION OF OFFICIAL ANALITICAL CHEMISTS AOAC. Official methods of analysis. 12.ed. Washington, D.C.: 1975.1094 p.

BARBOSA, H.P.; FIALHO, E.T.; FERREEIRA, A.S. et al. Triguilho para suínos nas fases inicial de crescimento, crescimento e terminação. Revista da Sociedade Brasileira de Zootecnia, v.21, n.5, p.827-37, 1992.

R. Bras. Zootec., v.31, n.2, p.982-990, 2002 (suplemento)
BELLAVER, C.; FIALHO, E.T.; PROTAS, J.F.S. et al. Radícula de malte na alimentação de suínos em crescimento e terminação. Pesquisa Agropecuária Brasileira, v.20, n.8, p.969-74, 1985.

EMPRESA BRASILEIRA DE PESQUISA E AGROPECUÁRIA - EMBRAPA. Tabela de composição química e valores energéticos de alimentos para suínos e aves. 3.ed. Concórdia: Centro Nacional de Pesquisa de Suínos e Aves, 1991.97p. (Documentos, 19).

GREEN, S.; KIENER, T. Digestibility of nitrogen and amino acids in soya-bean, sunflower, meat and rapeseed meals measured with pigs and poultry. Animal Production, v.48, p.157-179. 1989.

HEGEDUS, M.; FEKETE, S. Nutritional and animal health aspects of the substitution of soyabean meal with sunflower meal Magyar - Allatorvosok, v.49, n.10, p.597-604, 1994.

JONGBLOED, R.; KROONSBERG, C.; KAPPERS, I.E. et al. Estimating the feeding value of solvent extracted sunflower oilmeal and high grade feed barley in vitro and in vivo. Lelystad: Instituut-voor-Veevoedingsonderzoek, 1992. 45p. (Rapport, 237).

KENNELLY, J.J.; AHERNE, F.X. The effect of fiber formulated to contain different levels of energy and protein on digestibility coefficients in swine. Canadian Journal of Animal Science, v.60, p.717-726, 1980.

LIMA, G.J.M.M.; GOMES, P.C.; BARBOSA, H.P. et al. Digestibilidade aparente da proteína e valores energéticos de alguns alimentos para suínos. In: REUNIÃO ANUAL DA SOCIEDADE BRASILEIRA DE ZOOTECNIA, 26., 1989, Porto Alegre. Anais... Porto Alegre: Sociedade Brasileira de Zootecnia, 1989. p.202.

MATTERSON, L.D.; POTTER, L.M.; STUTZ, M.W. et al. The metabolizable energy of feed ingredients for chikens. Research Report, v.7, p.3-11, 1965.

MINARDI, I. Estudo sobre a composição bromatológica e coeficiente de digestibilidae do farelo e da torta de girassol. Piracicaba: Escola Superior de Agricultura Luiz de Queiroz, 1969. 49p. Dissertação (Mestrado em Zootecnia) - Escola Superior de Agricultura Luiz de Queiroz, 1969.

NATIONAL RESEARCH COUNCIL - NRC. Nutrient requeriments of swine. 10.ed. Washington, D.C.: National Academy Press, 1998. 189p.

SEERLEY, R.W.; BURDICK, D.; RUSSOM, W.C. et al. Sunflower meal as a replacement for soybean-meal in growing swine and rat diets. Journal of Animal Science, v.38, p.947-953, 1974.

SZABO, C.; JANSMAN, A.J.M.; VERSTEGEN, M.W.A. et al. The effect of dietary protein source on fattening performance and meat quality of pigs. Landbauforschung Volkenrode, v.193, p. 259-263, 1999.

SZELENYI, G.M.; FEBEL, H., ZSOLNAI, H. et al. Effects of extrusion of soyabean and sunflower meal-maize mixtures on apparent ileal and faecal digestibilities of nutrients in pigs. Allattenyesztes-es-Takarmanyozas, v.43, n.5-6, p.459-70, 1994.

STOTHERS, S.C.; FROESE, C.F. Performance of growing-pigs fed sunflower meal. Canadian Journal of Animal Science, v.62, p.1269, 1982

TRINDADE NETO, M.A.; LIMA, J.A.F.; FIALHO, E.T. et al. Farelo de glúten de milho (FGM) para suínos em crescimento e terminação (desenvolvimento). Revista da Sociedade Brasileira de Zootecnia, v.24, n.1, p.108-116, 1995.

WETSCHEREK, W.; LETTER, F.; KNAUS, W. Use of dehuleed sunflower meal in diet for pig fattening. Bodenkultur, v.44, n.1, p.89-97, 1993.

UNIVERSIDADE FEDERAL DE VIÇOSA - UFV. SAEG Sistema de análises estatísticas e genéticas. Versão 7.1 Viçosa, MG, 1997. 150p.

Recebido em: 04/04/01 Aceito em: 08/01/02 